\title{
ANALYSING THE LAW OF DYNAMIC SUBSIDENCE IN MINING AREA BY FUSING INSAR AND LEVELING MEASUREMENTS
}

\author{
Z. F. Yang ${ }^{\text {a,* }}$, Z. W. Li ${ }^{\text {a }}$ J. J. Zhu', J. Hu', Y. J. Wang ${ }^{\text {b }}$, G. L. Chen ${ }^{\text {b }}$
}

\author{
${ }^{a}$ School of Geosciences and Info-physics Engineering, Central South University, Changsha, 410083, China \\ b Jiangsu Provincial Key Lab of Resources and Information Engineering, China University of mining and Technology, \\ Xuzhou, 221116, China
}

KEY WORDS: Dynamic subsidence, Prediction, Feature point lost, InSAR, Leveling, Logistic time function

\begin{abstract}
:
Understanding the law of mining surface dynamic subsidence plays an important role in protecting the villages and other infrastructures against subsidence damage and disturbance. Unfortunately, the existed methods are mostly based on a few sparse leveling measurements, the accuracy and reliability of which are degraded when the feature points of the leveling measurements are lost in the processing of subsidence evolution. This paper presents a method to analysing the law of mining surface dynamic subsidence by fusing interferometric synthetic aperture radar (InSAR) and leveling measurements. By comparing the fitted results obtained by fusing InSAR/leveling and those only by independent leveling, it is shown that the InSAR/levelling fusion not only can make up the deficiency when the leveling measurements lost the feature points of dynamic subsidence, but also can improve the accuracy and reliability of results.
\end{abstract}

\section{INTRODUCTION}

Ground subsidence and movement caused by underground mining may damage buildings, railways, roads and any other infrastructures located in the subsidence basin. In order to assess the potential damages, surface subsidence should be known. However, the predicted results obtained by conventional approaches, such as influence function, empirical formulas, or numerical models (Nicieza et al, 2005), are final displacement measurements. Thus some new problems are arisen, for instance, for supercritical condition, the bottom of the final subsidence basin is flat, and the surface slope and curvature are zero (Peng et al, 1992), which means no surface deformation and no damages to those structures located in the subsidence basin bottom, nevertheless, the surface slope and curvature are occurred during advancing working face, So the potential damages of dynamic deformation must not be overlooked, and the law of mining surface dynamic subsidence should be investigated.

Ground subsidence and movement processes are timedependent, thus it is of great importance to select a proper time function to analyse the mining surface dynamic subsidence and movement. At present, the time function mainly includes Knothe time function (Knothe, 1952; Lbrahim et al, 2012), double parameters time function (Kwinta et al, 1996), generalized time function (Komalski, 2001), S-shaped growth time function (Wang et al, 2011; Zhang et al, 2009). The Knothe time function have been used widely due to only one unknown parameter, but the first order derivative (i.e. velocity of subsidence) and second order derivative (i.e. acceleration of subsidence) of which are not agreed with the actual process (Peng et al, 2004), so the accuracies of the results are low. On the contrary, the S-shaped growth model time function has better agreement with the evolution of mining surface subsidence than the others.
Furthermore, estimating the unknown parameters of time function is another important thing since a proper time function has been selected. Traditionally, the main approaches of estimating the unknown parameters are empirical methods (Cui et al, 1999) and fitting with the field measurements (Said et al, 1995). However, the unknown parameters are related to many factors, so the result predicted by empirical method is less accurate. For the later method, considering the limitations of conventional surveying approaches, such as high-cost, labour intensive, time consuming and so on, it is very difficult to measure all mining area with short time interval, and the feature point of the evolution of mining surface subsidence and movement may be lost. Thus the accuracy of unknown parameters will be reduced significantly.

Interferometric Synthetic Aperture Radar (InSAR) is a remote sensing technique which capable of producing high-resolution displacement maps with sub-centimeter accuracy. Combining InSAR and conventional field measurements not only can append extra redundant observations to estimate the unknown parameters of time function, but also can make up the deficiency when the leveling measurements lost the feature points of dynamic subsidence and improve the reliability and accuracy of result. Therefore, this paper presents a method to analyse the law of mining surface dynamic subsidence by fusing InSAR and leveling measurements. Firstly, we obtained 3 time periods accumulated deformation by exploiting 4 SAR images captured by Advanced Land Observing Satellite (ALOS) Phased Array type L-band Synthetic Aperture Radar (PALSAR) over a coal mine of Huaibei. Then, the unknown parameters of six points in this coal mine area are fitted by fusing 3 time periods InSAR and 10 time periods leveling measurements. .

\section{METHODOLOGY}

2.1 Principle of logistic time function

E-mail: successfullife2008@163.com 
The formation of final subsidence trough is very complicated, which can be mainly simplified as three phases: initial subsidence, main subsidence and residual subsidence (Jarosz et al, 1990). The logistic time function, which is one of S-shaped growth model time function, also has the same characters with the time flying. Logistic function is a common sigmoid function and named by Pierre François Verhulst who studied it in relation to population growth. Verhulst pointed out that the growth rate of individuals $\frac{d N(t)}{d(t)}$ decrease with the increasing of number of individuals $N(t)$ at time $t$. When $N(t)$ is equal to the carrying capacity $N_{m}$ (i.e. maximum number of individuals that the environment can support), the growth rate is equal to zero. So the equation can be expressed as

$$
\frac{d N(t)}{d(t)}=r \cdot N(t) \cdot\left[1-\frac{N(t)}{N_{m}}\right]
$$

where $r$ is intrinsic growth rate, which is a constant.

According to the initial condition: $t=0, \quad N(t)=N(0)$, hypothesis $a=\left(N_{m}-N(0)\right) / N(0)$, the solution of equation (1) is thus logistic function, i.e.

$$
N(t)=\frac{N_{m}}{1+a e^{-b t}}
$$

where $N_{m}, a$ and $b$ are unknown parameters required to be estimated.

If the logistic function is used to predict mining surface dynamic subsidence, the format of the equation can be rewriten as:

$$
W(t)=\frac{W_{m}}{1+a e^{-b t}}
$$

where $W_{m}, a, b$ are also unknown parameters. $W_{m}$ denotes the maximum possible subsidence, $a$ and $b$ are influence on the initiate time and velocity of subsidence, respectively.

\subsection{Method of experiment}

The deformation obtained by traditional InSAR technology is along the line of sight (LOS) direction, which is contributed by the displacements in the north, east and up directions. However, we want to analyze the law of mining surface dynamic subsidence by fusing subsidence measurements monitored by leveling and InSAR technologies, that is to say the displacement component in the up direction has to be obtained.

The maximum component of mining surface displacement caused by underground mining is subsidence (Peng et al, 1992), so we can get the subsidence $W$ by ignoring the horizontal movement components from LOS deformation map, i.e. $W=L O S / \cos \theta$, where $\theta$ is the incidence angle of SAR sensor. The comprehensive processing flow of analysing the law of mining surface dynamic subsidence by fusing InSAR and levelling measurements is described as follows.
1) Obtaining mining surface subsidence from LOS deformation map by ignoring horizontal components;

2) Getting time-series subsidences $\left[W\left(t_{1}\right), W\left(t_{2}\right), \cdots W\left(t_{n}\right)\right]^{T}$ of observation point from InSAR and leveling measurements in the time $\left[t_{1}, t_{2}, \cdots, t_{n}\right]^{T}$, and hypothesis the first monitoring time is 1 (including InSAR and leveling monitoring time), i.e. $t_{1}=1$

3) Calculating the time interval $\Delta t_{i}$ between the remaining monitoring time (i.e. $\left[t_{2}, \cdots, t_{n}\right]^{T}$ ). Thus we can get a new monitoring time $\left[1, \Delta t_{2}, \cdots, \Delta t_{n}\right]^{T}$ and time-series subsidences $\left[W(1), W\left(\Delta t_{2}\right), \cdots W\left(\Delta t_{n}\right)\right]^{T}$;

4) Considering the equation (3) is complicated, we estimate the unknown parameters (including $N_{m}, a$ and $b$ ) by fitted algorithm. Set $\left[1, \Delta t_{2}, \cdots, \Delta t_{n}\right]^{T}$ and $\left[W(1), W\left(\Delta t_{2}\right), \cdots W\left(\Delta t_{n}\right)\right]^{T}$ as independent variable and dependent variable, respectively, and then we fitted the unknown parameters based on equation (3).

The law of mining surface dynamic subsidence can be understood when the unknown parameters are estimated

\section{EXPERIMENTS AND RESULTS}

In this paper, four SAR images (Frame: 660, Track: 449) over a coal mine of Huaibei were acquired by ALOS PALSAR. The time of acquisitions span from October 13, 2009 to May 28 2010, the amplitude image is shown in Figure 1. Consequently, three interferometric pairs are generated by adjacent SAR acquisitions, the parameters of that are shown in Table 1 .

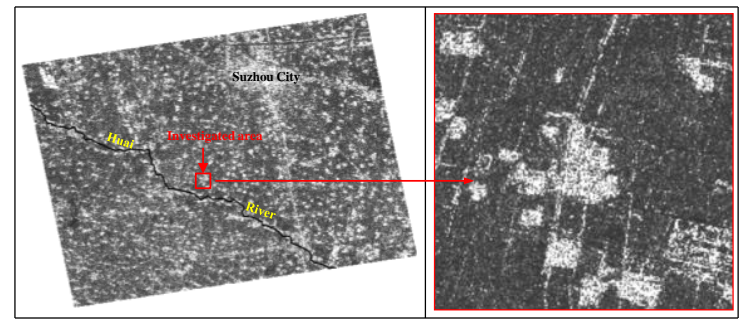

Figure 1. SAR amplitude image of investigated area.

Table 1 Parameters of interferometry

\begin{tabular}{ccccc}
\hline $\begin{array}{c}\text { Series } \\
\text { Number }\end{array}$ & $\begin{array}{c}\text { Master } \\
(\text { yy-mm-dd) }\end{array}$ & $\begin{array}{c}\text { Slave } \\
\text { (yy-mm-dd) }\end{array}$ & P B*(m) & $\begin{array}{c}\text { Time } \\
(\mathrm{d})\end{array}$ \\
\hline 1 & $2009-10-13$ & $2010-01-13$ & 356 & 92 \\
2 & $2010-01-13$ & $2010-02-28$ & 582 & 46 \\
3 & $2010-02-28$ & $2010-05-31$ & 255 & 92 \\
\hline
\end{tabular}

* P B denote the perpendicular baseline

In order to uniform the spatial coordinates of each SAR image, the remaining three SAR images were registered with that acquired in February 28, 2010. Then traditional DInSAR process is applied to retrieve deformation map of investigated area. Differential interferograms and accumulated deformation maps along the LOS direction are shown in Figure 2. 

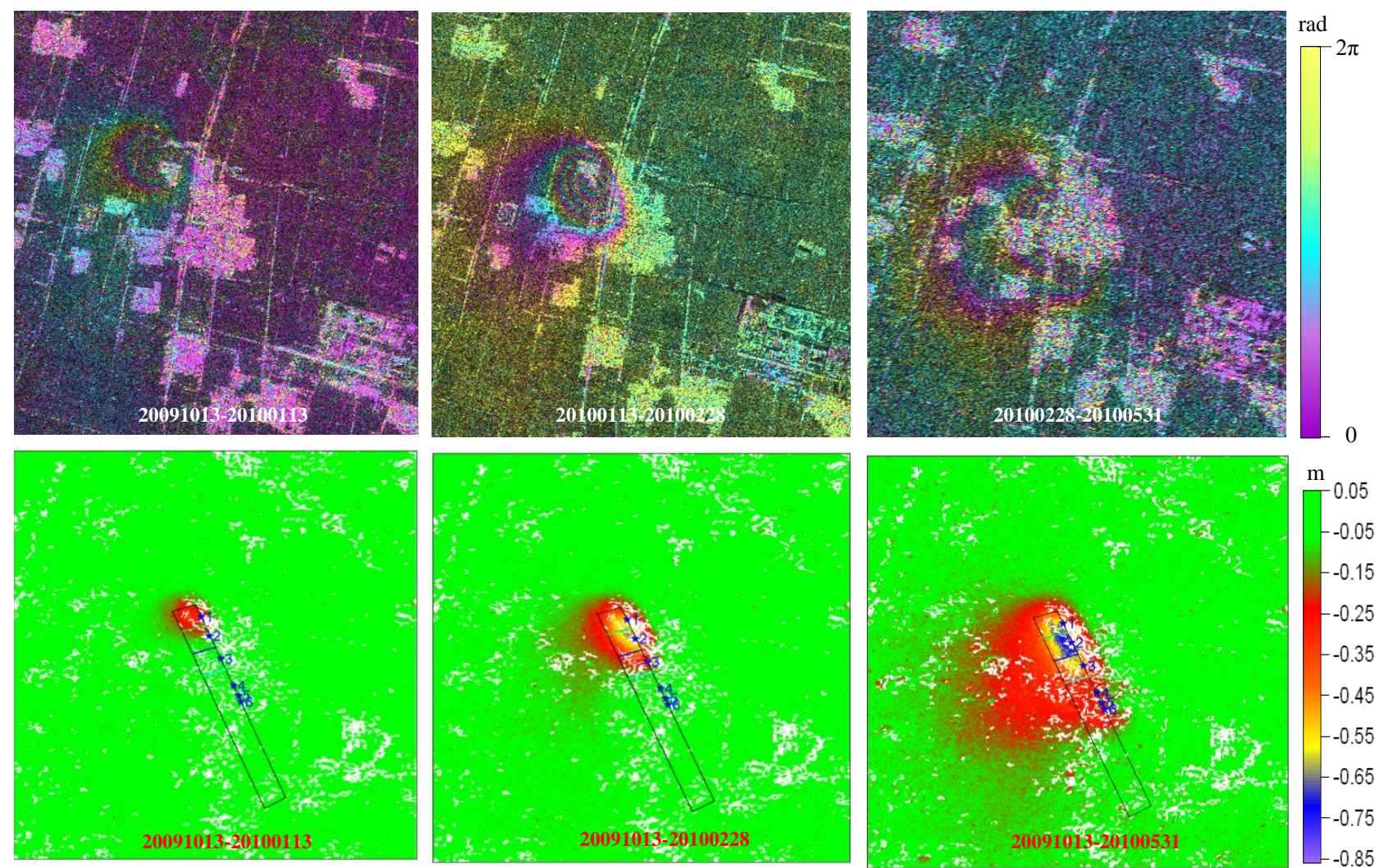

Figure 2. Differential interferograms (Up) and accumulated LOS deformation maps (Bottom) of investigated area. The black lines denote designed working face, and the green, blue and cyan line denotes the advance location in January 13, February 28 and May 31,2010 , respectively.

In order to use the LOS deformation maps directly, instead of these interpolated, six surveyed points above working face are selected to study the law of dynamic subsidence. Considering the deformation measured by InSAR is along the LOS direction, so we neglect the contributions of horizontal movements, that is the mining surface subsidence $W=\operatorname{LOS} / \cos \theta$. Consequently, 10 times leveling measurements (surveyed times are shown in Figure 3) and 3 times InSAR measurements of six points are applied to estimate the parameters of logistic time function.

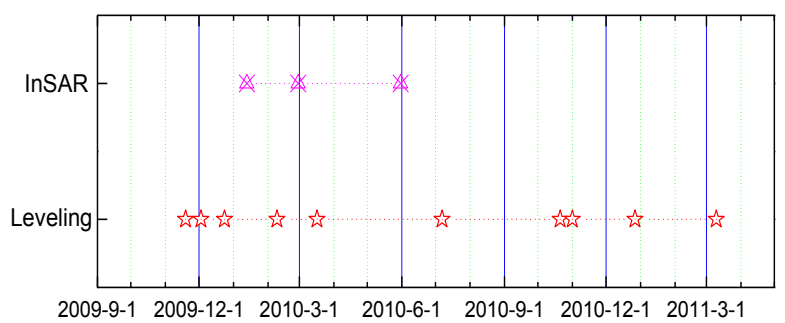

Figure 3. Observation dates of leveling and InSAR measurements

We can find that the InSAR measurements are good supplement for the leveling from Figure 3. In order to present the importance of fusing InSAR and leveling measurements to estimate parameters of logistic time function, we compare the difference of the logistic function fitted only by leveling measurements with these fitted by fusing InSAR and leveling measurements, and the results are shown in Figure 4.
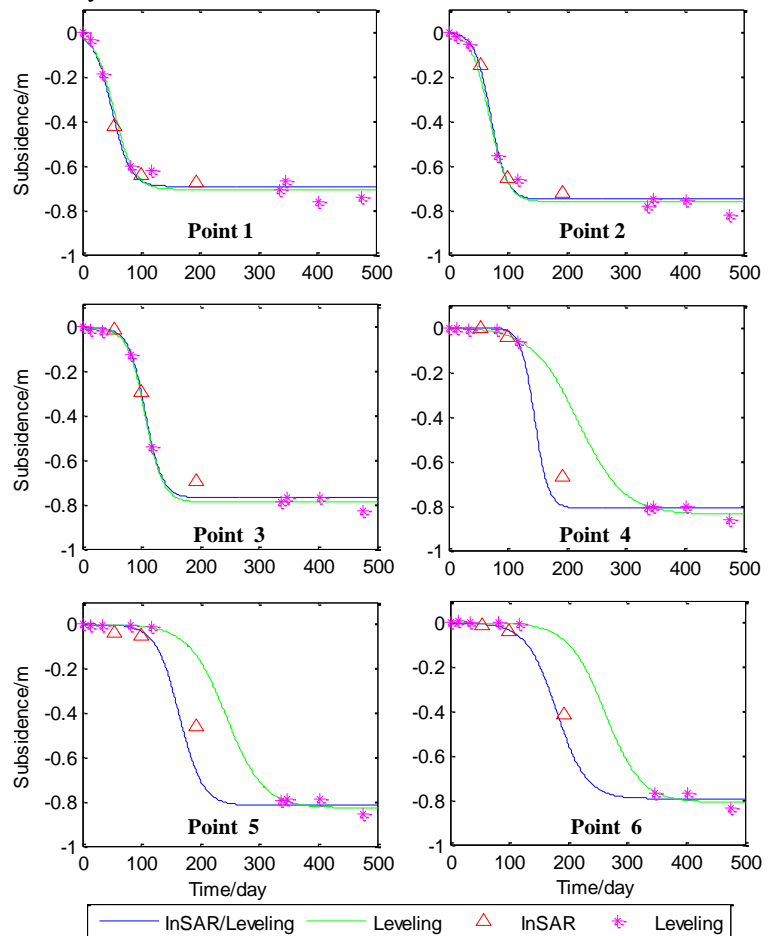

Figure 4. Logistic function fitted by fusing InSAR and leveling measurements (blue line) and that only by leveling measurements (green line).

We can see that the fitted logistic functions by InSAR/leveling and leveling have a small difference for point 13 , but the large difference is occurred in point 4-6 from Figure 4. The reasons resulted in that are the observation times of 
leveling measurements can roughly summarize the evolution of dynamic subsidence for point $1-3$, but cannot do that for point 4-6. In addition, the observation time in May 31, 2010 is appeared in the main subsidence phase, and the measurement can restrain the accelerate subsidence process of logistic time function. This can account for the reliabilities of the results fitted by InSAR/leveling are high than these by leveling for point 4-6. So fusing InSAR and leveling measurements to estimate the parameters of time function not only can improve the accuracy and reliability of results, but also can make up the deficiency when the leveling measurements lost the feature points of dynamic subsidence..

\section{CONCLUSIONS}

This paper presents a method to estimate the parameters of time function of dynamic subsidence prediction by fusing InSAR and leveling measurements. The experiments show that the presented method not only can append extra redundant observations to estimate the unknown parameters of time function, but also can make up the deficiency when the leveling measurements lost the feature points of dynamic subsidence and improve the reliability and accuracy of prediction.

\section{Acknowledgements}

The ALOS PALSAR data were provided by the Japan Aerospace Exploration Agency (JAXA) (No. P5820002 ), The work was supported by the National Natural Science Foundation of China (Nos.: 41222027 and 40974006), National Key Basic Research and Development Program of China (No. 2012CB719903), Fundamental Research Funds for the Central Universities of Central South University (2013zzts249).

\section{References}

Cui X. M., Miu X. X., Zhao Y. L., 1999. Discussion on the time function of time dependent surface movement. Journal of China Coal Society, 24(5), pp.453-456.

Jarosz A., Karmis M., Sroka A.., 1990. Subsidence development with time-experiences from longwall operations in the Appalachian coalfield. International Journal of Mining and Geological Engineering, 8, pp. 261-273.

Knothe S., 1952. Time influence on a formation of a subsidence surface. Archiwum Gornicwai I Huticwa, 1(1), pp.1-3.

Komalski A., 2001. Surface subsidence and rate of its increments based on measurements and theory. Archives of Mining Science, 46(4), pp. 391-406.

Kwinta A., Hejmanowski R., Sroka A., 1996. A time function analysis used for the prediction of rock mass subsidence. In: Proceeding of the International Symposium on Mining Science and Technology, Xuzhou, pp. 419-421

Lbrahim D., Yasuhiro M., Hiro L., 2012. GIS-Based computational method simulating the components of $3 \mathrm{D}$ dynamic ground subsidence during the process of undermining. International Journal of Geomechanics, 12, pp. 43-53.

Nicieza G. C., Fernándaz Á. M. I., Díaz M. A., 2005. The new three-dimensional subsidence function denoted by n-k-g.
International Journal of Rock Mechanics and Mining Sciences, 42, pp.372-387.

Peng S. S., Ma W. M., Zhong W. L., 1992. Surface subsidence engineering. Society for Mining, Metallurgy \& Exploration, Incorporated, New York.

Peng X. Z., Cui X. M., Zang Y. Q., et al, 2004. Time function and prediction of progressive surface movements and deformations. Journal of University of Science and Technology Beijing, 26(4), pp. 341-344.

Said S., 1995. Dynamic subsidence prediction over longwall mining in Abu-Tartur mines, Egypt. In: Proceedings of the Fifth International Symposium on Land Subsidence, The Hague, pp.161-166.

Wang Z. S., Deng K. Z., 2011. Richards model of surface dynamic subsidence prediction in mining area. Rock and Soil Mechanics, 32(6), pp.1664-1668.

Zhang W. Z., Zou Y. F., Ren X. F., 2009. Research on logistic model in forecasting subsidence single-point during mining. Journal of Mining \& Safety Engineering, 26(4), pp.486-489. 